\title{
Wiener Index of Some Thorn Graphs
}

\author{
A. Sumathi \\ Department of Mathematics, Seethalakshmi Ramaswami College, Tiruchirappalli-2
}

\begin{abstract}
The Wiener index is one of the oldest molecular-graph-based structure-descriptors. The study of Wiener index is one of the current areas of research in mathematical chemistry. It also gives good correlations between Wiener index (of molecular graphs) and the physico chemical properties of the underlying organic compounds. That is, the Wiener index of a molecular graph provides a rough measure of the compactness of the underlying molecule. The Wiener index W(G) of a connected graph $G$ is the sum of the distances between all pairs (ordered) of vertices of $\mathbf{G}$. $W(G)=\frac{1}{2} \sum_{u, v} d(u, v)$.A thorn graph G* can be generated from a parent graph $G$ by attaching $p$ new vertices to each vertex of $G$. The basic concepts of thorn graphs proposed by Gutman are extended to the wider concept of generalized thorny graphs. In this paper, WienerIndex of some classes of (generalized) thorn graphs like thorn paths, thorn cycle, thorn stars through MATLAB is presented.
\end{abstract}

Keywords: Thorn graphs(generalized), Wiener number, Thorn rings, Thorn stars, Thorn rods

\section{Introduction}

The Wiener index $\mathbf{W}(\mathbf{G})$ is a distance-based topological invariant much used in the study of the structure-property and the structure-activity relationships of various classes of biochemically interesting compounds introduced by Harold Wiener in 1947 for predicting boiling points b. p of alkanes based on the formula

$b \cdot p=\alpha W+\beta w(3)+\gamma$

Where $\alpha, \beta, \gamma$ are empirical constants, and $\mathrm{w}(3)$ is called path number. It is defined as the half sum of the distances between all pairs of vertices of $\mathrm{G}$.

$W(G)=\frac{1}{2} \sum_{u, v \in G} d(u, v)$

Where $d(u, v)$ is the number of edges in a shortest path connecting the vertices $u$ \& $v$ in $G[8]$

Notation:

$W(G)=\frac{1}{2} \sum_{u, v \in G} d(u, v)=\sum_{u<v} d(u, v)=\sum_{i<j} d\left(u_{i}, u_{j}\right)$

\section{Definitions and Preliminaries}

Ournotationisstandardandmainlytakenfromstandardbooksofg raphtheory [1]. In this paper, the researcher considers finite, nontrivial, simple and undirected graphs. For a graph $\mathrm{G}$, the researcher denotes by $\mathrm{V}(\mathrm{G})$ and $\mathrm{E}(\mathrm{G})$, its vertex and edge sets, respectively. Gutman[4,5] introduced the concept of thorn graph for any graph $G^{*}$ that can be obtained from a parent connected graph $\mathrm{G}$ by attaching $\mathrm{p}_{\mathrm{i}}>0$ new vertices of degree one to each vertex $i$. Bonchev and Klein [2] reported additional formulas for the Wiener index of thorn trees, thorn rods, thorn rings, and thorn stars. These thorn graphs are transformed into some AliphaticHydrocarbons in Molecular chemistry. In this paper, we find the Wiener index of some thorn graphs from a parent graphs path, cycle,star through MATLAB.

Definition 2.1:[3] $\mathrm{P}_{n}$ stands for a path with $\mathrm{n}$ vertices, while $\mathrm{P}_{\mathrm{n}, \mathrm{p}, \mathrm{k}}$ denotes a tree obtained from $\mathrm{P}_{\mathrm{n}}$ by adding $\mathrm{p}$ neighbors to each of its nonterminal vertices and $\mathrm{k}$ neighbors to each of its terminal vertices.

Definition 2.2:[2] A caterpillar is a thorn tree $T^{*}(a, b)$ whose nonterminal verticesb $\geq 1$ are of the same degree $a>2$, and whose parent graph is the b-sitechain graph, $\mathrm{P}_{\mathrm{b}}$.

Theorem 2.2.1: The Wiener number of a caterpillar having $b$ branched vertices ofdegree $a$ is: $\mathrm{W}\left(\mathrm{T}^{*}(\mathrm{a}, \mathrm{b})\right)=\frac{1}{6} \mathrm{~b}(\mathrm{a}-1)[(\mathrm{a}-$ 1) $(b-1)(b+7)+6(a+1)]+1$

Definition 2.3:[2] A thorn rod is a graph, $\mathrm{P}_{\mathrm{p}, \mathrm{t}}$ which includes a linear chain (termed»rod «) of $p$ vertices and degree- $t$ terminal vertices at each of the two rodends.

Theorem 2.3.1: The Wiener number of a thorn $\operatorname{rod} \mathrm{P}_{\mathrm{p}, \mathrm{t}}$ is $\mathrm{W}\left(\mathrm{P}_{\mathrm{p}, \mathrm{t}}\right)=\frac{1}{6}\left(\mathrm{p}^{3}-\mathrm{p}\right)+(\mathrm{t}-1)^{2}(\mathrm{p}+3)+(\mathrm{t}-1)\left(\mathrm{p}^{2}+\mathrm{p}-2\right)$.

Definition 2.4:[2] Thorn stars are graphs obtained from a $k$ arm star by attachingt-1 terminal vertices to each of the star arms.

Theorem 2.4.1: The Wiener number of a thorn star $\mathrm{S}_{\mathrm{k}, \mathrm{t}}$ is $W\left(\mathrm{~S}_{\mathrm{k}, \mathrm{t}}\right)=\mathrm{kt}(2 \mathrm{kt}-\mathrm{k}-\mathrm{t}+1)$

Definition 2.5:[2] A $+\mathrm{t}$-thorny ring has a simple cycle as the parent, and $\mathrm{t}-2$ thorns at each cycle vertex.

Theorem 2.5.1: The Wiener number of a t-thorny ring having $n$ ring-vertices is

$\mathrm{W}=\frac{1}{8} \mathrm{n}(\mathrm{t}-1)^{2}\left(\mathrm{n}^{2}-\mathrm{a}\right)+\mathrm{n}(\mathrm{t}-2)(\mathrm{nt}-\mathrm{n}-1)$ with $\mathrm{a}=0$ for $\mathrm{n}-$ even, and $\mathrm{a}=1$ for $\mathrm{n}-$ odd.

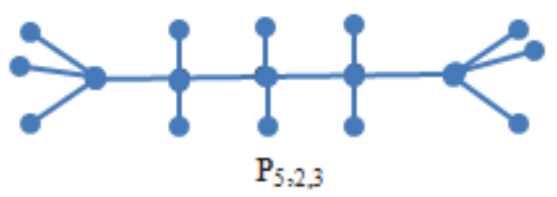



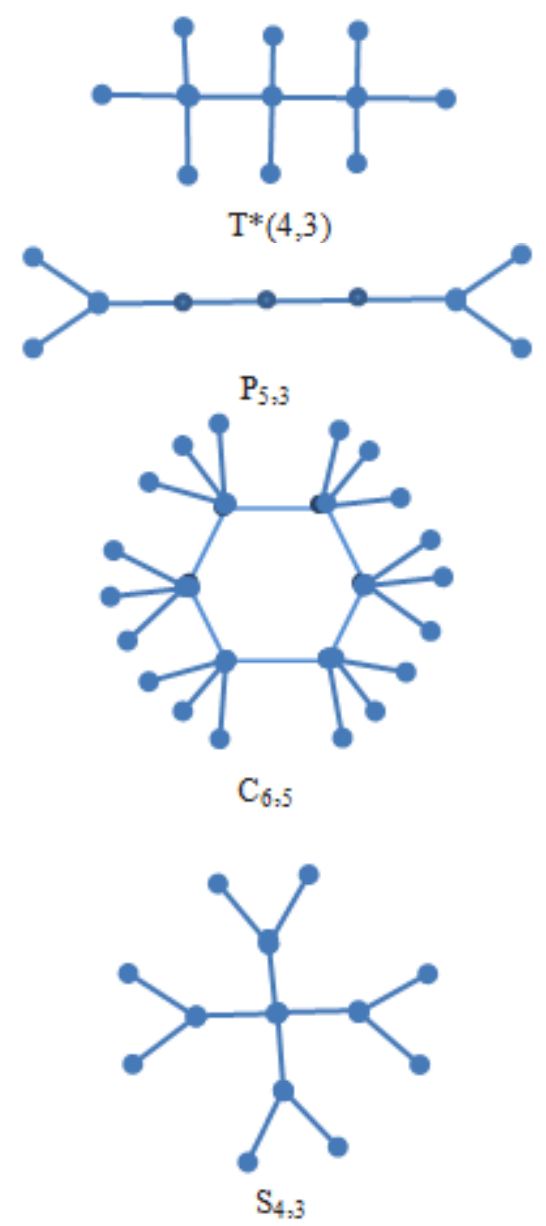

If $\mathrm{G}$ is a molecular graph with $\mathrm{n}$ nodes, then its adjacency matrix $A_{i j}$ is a square matrix of order $n$ defined as $a_{i j}=1$, if there is an link between $i^{\text {th }}$ and $j^{\text {th }}$ nodes, $a_{i j}=0$, if there is no link between them. The Program for finding Wiener index of any graphs through Adjacency matrix given in $[6,7]$. The following program computes the Adjacency matrix of above generalized graphs through MATLAB.

\section{Program for Finding Wiener Index andEnergy level of Thorn Graphs}

\section{Program 3.1:}

\%This MATLAB Program calculates the Wienerindex and Energy level of Thornpath graphs

clc

clearall

$\mathrm{n}=$ input('No. of vertices in a Path $\mathrm{n}=$ ');

$\mathrm{p}=\operatorname{input}($ 'No. of thorns at the non terminal nodes $\mathrm{p}=$ ');

$\mathrm{k}=$ input('No. of thorns at the terminal nodes $\mathrm{k}=$ ');

$\mathrm{s}=\mathrm{n}+((\mathrm{n}-2) * \mathrm{p})+(2 * \mathrm{k})$

$\mathrm{A}=[\mathrm{]}$;

for $\mathrm{i}=1: \mathrm{n}-1$

$\mathrm{A}(\mathrm{i}, \mathrm{i}+1)=1 ; \mathrm{A}(\mathrm{i}+1, \mathrm{i})=1$;

end

for $\mathrm{i}=2: \mathrm{n}-1$

$\mathrm{u}=(\mathrm{j} * \mathrm{p})+1:(\mathrm{j}+1) * \mathrm{p}$;

for $\mathrm{q}=\mathrm{u}$

$\mathrm{A}(\mathrm{i}, \mathrm{n}+\mathrm{q})=1 ; \mathrm{A}(\mathrm{n}+\mathrm{q}, \mathrm{i})=1$;

end

$\mathrm{j}=\mathrm{j}+1$; end

for $\mathrm{j}=1: \mathrm{k}$ end

$$
A(1, n+((n-2) * p)+j)=1 ; A(n+((n-2) * p)+j, 1)=1 ;
$$

for $\mathrm{j}=\mathrm{k}+1: 2 * \mathrm{k}$ end

$$
A(n, n+((n-2) * p)+j)=1 ; A(n+((n-2) * p)+j, n)=1 ;
$$

A;

$\mathrm{G}=\operatorname{sparse}(\mathrm{A})$;

$\mathrm{DM}=$ graphallshortestpaths $(\mathrm{G}$, 'directed',false $)$;

$\mathrm{M}=\operatorname{sum}(\operatorname{sum}(\mathrm{DM}))$;

fprintf('Wiener index of thron path, $W=\% d \backslash n ', M / 2$ )

$\%$ Energy level of $\mathrm{G}$

$\mathrm{EV}=\mathrm{eig}(\mathrm{A})$;

SpectralRadiusofG $=\max (\mathrm{EV})$;

$\mathrm{E}=\operatorname{abs}(\mathrm{EV})$;

Energy $=\operatorname{sum}(\operatorname{sum}(E))$;

if Energy $>(2 * \mathrm{~s})-2$

$\operatorname{disp}($ ' $G$ is Hyper energetic')

elseif Energy $<=(2 * s)-2$

$\operatorname{disp}(' G$ is NonHyper energetic')

end

if Energy $<\mathrm{s}$

$\operatorname{disp}(' G$ is Hypo energetic')

elseif Energy $>=\mathrm{s}$

disp('G is Nonhypo energetic')

end

$\mathrm{UG}=\operatorname{tril}\left(\mathrm{G}+\mathrm{G}^{\prime}\right)$

view(biograph(UG,[],'ShowArrows','off,'ShowWeights','off' ))

\section{Program 3.2:}

\%This MATLAB Program calculates the Wiener index of thorn star

$\%$ Adjacency matrix of thorn star

$\mathrm{m}=$ input('No. of vertices in a star $\mathrm{m}=$ ');

$\mathrm{n}=$ input('No. of thorns at the terminal vertex $\mathrm{n}=$ ');

$\mathrm{A}=[\mathrm{]}$;

for $\mathrm{i}=2: \mathrm{m}$

$\mathrm{A}(1, \mathrm{i})=1 ; \mathrm{A}(\mathrm{i}, 1)=1$;

end

for $\mathrm{i}=2: \mathrm{m}$

for $k=\left(j^{*} n\right)+1:\left((j+1)^{*} n\right)$

$\mathrm{A}(\mathrm{i}, \mathrm{m}+\mathrm{k})=1 ; \mathrm{A}(\mathrm{m}+\mathrm{k}, \mathrm{i})=1$;

end

$\mathrm{j}=\mathrm{j}+1$;

end

A;

\section{Program 3.3:}

\%This MATLAB Program calculates the Wiener index of thorn cycle

$\%$ Adjacency matrix of thorn cycle

$\mathrm{m}=$ input('No. of vertices in a cycle $\mathrm{m}=$ ');

$\mathrm{n}=$ input('No. of thorns at each vertices $\mathrm{n}=$ ');

$\mathrm{A}=[\mathrm{]}$;

for $\mathrm{i}=1: \mathrm{m}-1$

$\mathrm{A}(\mathrm{i}, \mathrm{i}+1)=1 ; \mathrm{A}(\mathrm{i}+1, \mathrm{i})=1$;

$\mathrm{A}(1, \mathrm{~m})=1 ; \mathrm{A}(\mathrm{m}, 1)=1$;

end

for $\mathrm{i}=1: \mathrm{m}$ 


\section{International Journal of Science and Research (IJSR)}

ISSN (Online): 2319-7064

Index Copernicus Value (2013): 6.14 | Impact Factor (2014): 5.611

for $\mathrm{k}=(\mathrm{j} * \mathrm{n})+1:\left((\mathrm{j}+1)^{*} \mathrm{n}\right)$

$\mathrm{A}(\mathrm{i}, \mathrm{m}+\mathrm{k})=1 ; \mathrm{A}(\mathrm{m}+\mathrm{k}, \mathrm{i})=1$;

end

$\mathrm{j}=\mathrm{j}+1$;

end

$\mathrm{A}$

\section{Example1:}

For instance, the following is the execution of simple MATLAB Program in the command window for the thorn path graph $\mathrm{P}_{6,2,4}$ with Wiener index and Energy level

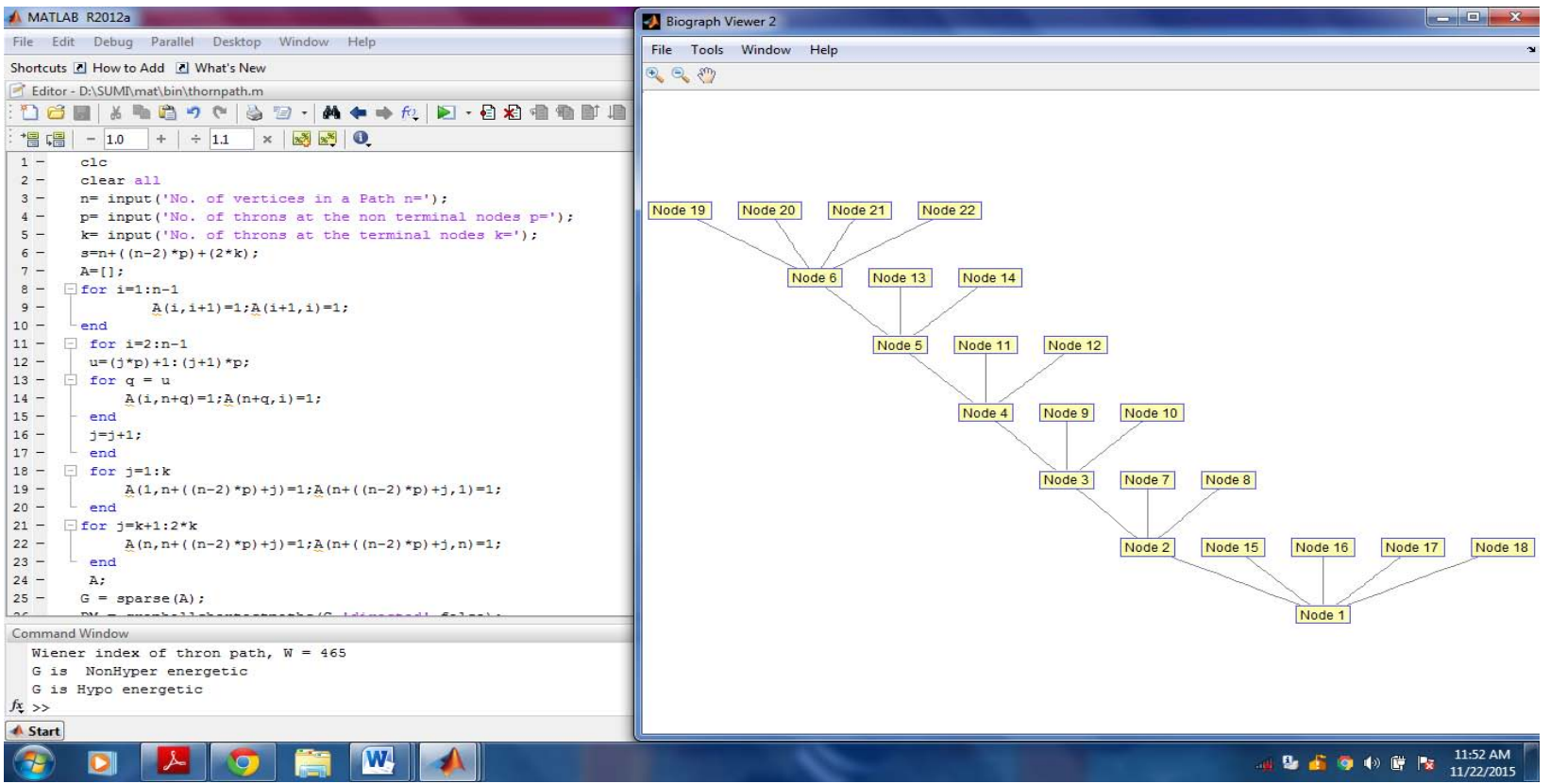

Example 2:

The following is the execution of simple MATLAB Program in the command window for the thornstar graph $\mathrm{S}_{4,4}$ with Wiener index and Energy level. Where $\mathrm{t}=\mathrm{n}+1$

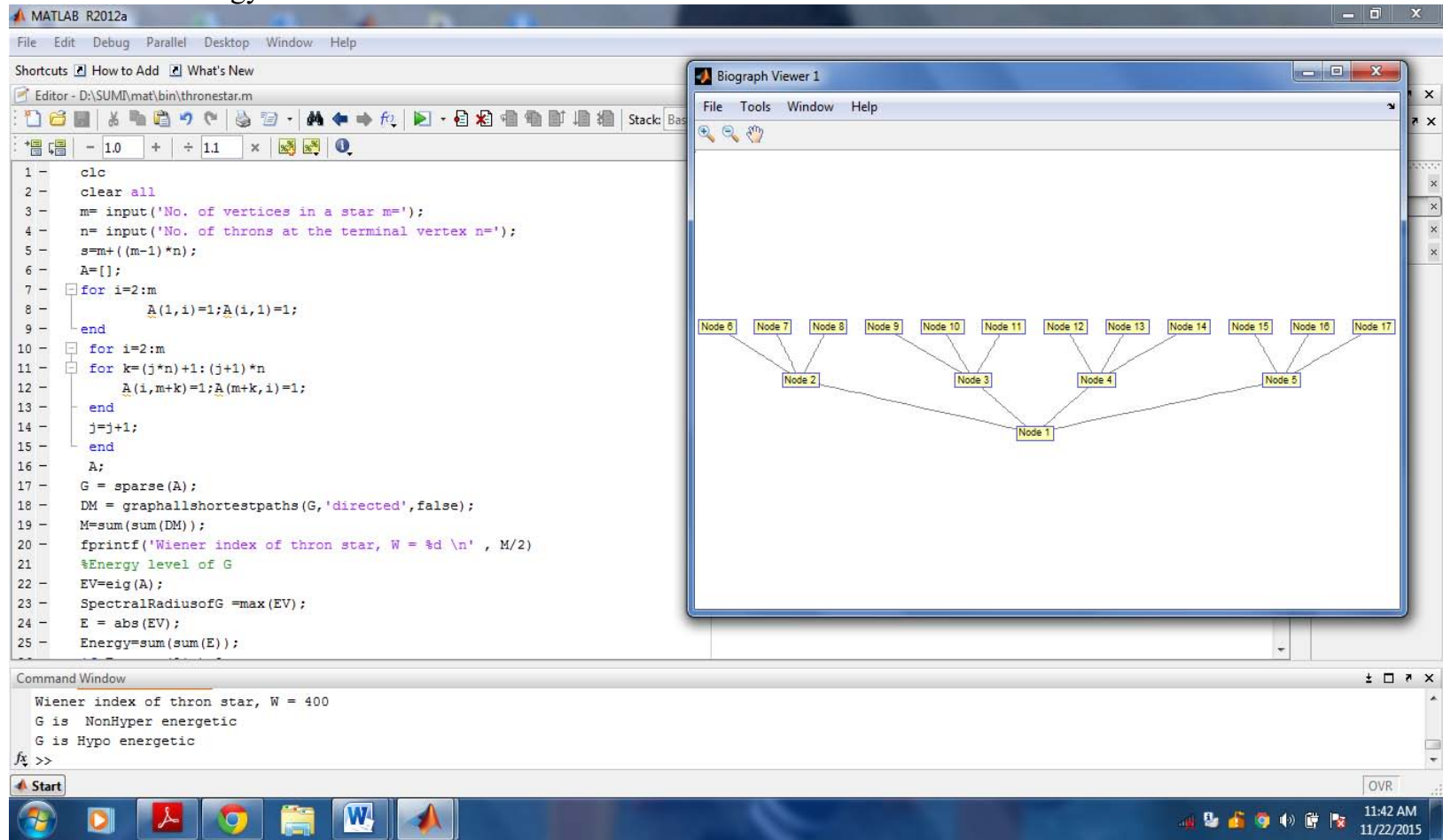

\section{Conclusion}

In this paper, MATLAB Program has been presented for computing the Wiener index, Energy level of some generalized thorn graphs. The researcher tested the above program to calculate the Wiener index and Energy level of above thorn graphs for arbitrary $m, n$

\section{References}

[1] Balakrishnan R \&Renganathan K, A Text book of graph theory, springer - verlag New York, (2000)

\section{Volume 4 Issue 11, November 2015}




\section{International Journal of Science and Research (IJSR) \\ ISSN (Online): 2319-7064}

Index Copernicus Value (2013): 6.14 | Impact Factor (2014): 5.611

[2] Bonchev .D and Klein D. J., On the Wiener Number of Thorn Trees, Stars, Rings and Rods, Croat. Chem. Acta2002, 75, 613-620.

[3] DamirVukicevic, Sonja Nikolic and NenadTrinajstic, On the Schultz index for thorn graphs, Internet Electronic Journal of Molecular Design July 2005, Volume 4, Number 7, Pages 501-514.

[4] Gutman.I, D. Vidovi\}, and L. Popovi\}, J. Chem. Soc., Faraday Trans. 94 (1998),857-860.

[5] Gutman.I, Publ. Inst. Math. (Beograd) 63(1998) 31-36.

[6] Thilakam K, Sumathi A, How to Compute the Wiener index of a graph using MATLAB, International Journal of Applied Mathematics\& Statistical Sciences ISSN: 2319-3972; Vol. 2, Issue 5, Nov 2013, 143-148.

[7] Thilakam K, Sumathi A, Wiener Index of Directed and Weighted graphs by MATLAB Program, IOSR Journal of Mathematics2278-5728,Vol.10,Issue. 5,Version-V (pp.67-71),2014.

[8] Wiener H, Structural determination of paraffin boiling points- J.Am chem. Soc.6 (1947) 17-20.

\section{Author Details}

A. Sumathi is currently working as an Assistant Professor in Department of Mathematics, Seethalakshmi Ramaswami College, Trichy-2, Tamil Nadu, India. She has more than 14 years of teaching experience in both Graduate and Post Graduate levels. She is specializedin the field of Molecular Graph Theory, Number Theory and Computational Programming. 